\title{
A FLAUTA DOCE: UM INSTRUMENTO MUSICALIZADOR DOS TEMPOS MODERNOS
}

\section{ARTIGO ORIGINAL}

BARBOSA, Fabiano Da Silva ${ }^{1}$

BARBOSA, Fabiano Da Silva. A flauta doce: Um instrumento musicalizador dos tempos modernos. Revista Científica Multidisciplinar Núcleo do Conhecimento. Ano 05, Ed. 05, Vol. 03, pp. 126-150. Maio de 2020. ISSN: 2448-0959, Link de acesso: https://www.nucleodoconhecimento.com.br/arte/flauta-doce

\section{RESUMO}

A fabricação de flautas doces em meados do século 20 levou à introdução deste instrumento nas salas de aula voltadas para a música. As flautas doces se tornaram muito populares nas escolas, já que são um dos instrumentos mais baratos para comprar e relativamente fáceis de tocar, já que são pré-ajustados. Muitos compositores e educadores buscam atualmente pela sua introdução nas escolas, aproveitando assim as possibilidades melódicas e de conjunto do instrumento. A flauta doce é o complemento perfeito para conjunto de instrumentos e vozes, pois mesmo um músico iniciante pode acompanhar os demais ou mesmo improvisar em alguns tons. No entanto, durante sua história, a flauta doce sofreu momentos em que ela acabou caindo no esquecimento dos músicos, onde veio a ressurgir no século 20 e com mais força ainda no século 21. Atualmente, temos que a sua utilização vem crescendo de forma considerável, devido à facilidade que a mesma oferece durante o aprendizado. Sendo assim, o presente estudo tem como objetivo familiarizar o leitor com o status da flauta doce como instrumento musical nos dias de hoje. As informações foram coletadas de textos e artigos disponíveis sobre o assunto para obter ideias mais recentes e precisas sobre sua história e utilização.

\footnotetext{
${ }^{1}$ Pós graduado em Educação Musical, graduação Licenciatura em Música.
} 
Palavras-Chave: Flauta Doce, musicalidade, Educação Musical.

\section{INTRODUÇÃO}

Muitas pessoas cometem o equívoco de considerar que a flauta doce não é um instrumento legítimo em nosso tempo. Assim, mostra-se extremamente necessário ilustrar para os músicos e compositores contemporâneos as possibilidades que existem para a flauta doce, como um meio de execução e como um meio de educação para jovens e idosos.

Para definir os precedentes da flauta doce, será relatado um breve histórico se sua existência. Assim, fica mais evidente como a flauta doce tornou-se um instrumento popular nos tempos antigos, e como ela atingiu o pico de seu desenvolvimento durante o final do período barroco. Durante o século XIX, a flauta doce começou a entrar em desuso, onde foi substituída pela flauta transversal. A música do período romântico não se prestava à natureza quieta da flauta doce, e esta é uma das razões para a perda de popularidade do instrumento.

No entanto, no final do século XIX, houve um renascimento do interesse em obras antigas, o que acabou levando à redescoberta da flauta doce como um meio de expressão da arte musical e literária. Arnold Dolmetsch e seu filho Carl Dolmetsch foram os pioneiros do ressurgimento da flauta doce no final do século XIX e início do século $\mathrm{XX}$, onde foi por eles que surgiram os meios pelos quais o instrumento foi reproduzido e divulgado no mundo musical. Por essa razão, estaremos incluindo nesse estudo sua biografia. No entanto, a contribuição para o ressurgimento da flauta doce não se deve somente a eles, mas a um conjunto de músicos que o sucederam ou mesmo acompanharam seus trabalhos com a flauta doce, conforme será retratado a seguir.

O fato de que tal homem existiu e de que ele recebeu um apoio considerável para empreender o ressurgimento da flauta doce mostra que era a hora certa para tal instrumento passar ser reconstruído em nosso século. As técnicas necessárias para a construção das flautas doces foram descobertas por ele e aplicadas ao modelo 
moderno adotado. Como resultado dessas técnicas, será ilustrado o status da flauta doce nos dias de hoje, incluindo sua estrutura física e a disposição utilizada para a execução de músicas.

\section{DESENVOLVIMENTO}

\section{HISTÓRIA DA FLAUTA DOCE}

A flauta doce, como a conhecemos hoje, tinha uma incerteza quanto a sua estrutura. Por exemplo, Adam Carse menciona que o bocal de uma flauta doce é estruturalmente mais complicado que o de uma flauta transversal, que é um pouco mais recente em desenvolvimento, embora hoje haja contestações a esse respeito. A flauta doce foi retratada pela primeira vez já no século $\mathrm{XI}$, onde os achados arqueológicos mais antigos datam de aproximadamente do século XVI. Os séculos entre estes dois citados anteriormente fornecem uma riqueza de literatura, pinturas e manuscritos que mencionar a flauta doce (BARROS, 2010).

No entanto, não se sabe ao certo onde a flauta doce surgiu como instrumento musical. Conforme citado anteriormente, sua primeira evidência histórica vem de uma miniatura francesa do século XI. Nos séculos XV e XVI, foram encontradas partituras musicais com indicações específicas para flauta doce. Nessas partituras, esse instrumento dobrava as linhas vocais, exceto em danças animadas escritas especificamente para instrumentos de outros tipos (LUFT, 1972).

A flauta doce foi amplamente encontrada na Holanda, de acordo com referências na literatura e imagens do tempo desse país. Ela ocupou um lugar de destaque também na Alemanha e na Inglaterra. Menestréis, amadores de classe média e bandas de corte usavam o instrumento em suas performances musicais. Ela também era bem conhecida e frequentemente usada na Espanha e Itália, onde ilustrações da época mostram a falta doce sendo usada com outros instrumentos ou mesmo sozinha. Consortes de flautas doces como unidade familiar provavelmente não se desenvolveu até o final do século XV. Isso se deve à preferência por um timbre diferente em cada uma das linhas contrapontísticas da música do período (BENASSI, 2017). 
A flauta doce era muitas vezes parte de um grupo que também incluía cornetas e trompetes. Foi usada tanto nas músicas sacras quanto seculares da época, embora nenhuma parte fosse realmente especificada para a flauta doce ou para quaisquer outros instrumentos. A música era em grande parte vocal e polifônica em caráter e favoreceu o consortes mistos de vozes e instrumentos. Na segunda metade do século XVI, a escola veneziana começou a usar famílias de instrumentos. Em 1599, Morley especificou a flauta doce como uma das partes das músicas tocadas na época. Durante o período Tudor (1485-1603) na Inglaterra, a flauta doce era bastante popular. Tanto Henrique VII quanto Henrique VIII empregaram flautas doces nas músicas, bem como tocavam o instrumento (PAOLIELLO, 2007).

A flauta doce alcançou grande popularidade nos séculos XVI e XVII. Esse desenvolvimento estava ligado ao fato de que a música de arte, em oposição à música folk, não era mais o domínio exclusivo da nobreza e do clero. O advento da imprensa tornou disponível para os plebeus mais ricos também. A popularidade do instrumento também chegou aos tribunais. Por exemplo, na morte de Henrique VIII em 1547, um inventário de suas posses incluía 76 flautas doces. Há também numerosas referências ao instrumento na literatura contemporânea, como por exemplo, Shakespeare e Milton (STORI, 2008).

Várias mudanças na construção de gravadores ocorreram no século XVII, resultando no tipo de instrumento geralmente chamado de flauta doce barroca, em oposição às antigas flautas doces do Renascimento. Essas inovações permitiram que as flautas doces barrocas possuíssem um tom considerado "mais doce" do que o dos instrumentos anteriores, à custa de uma redução no volume, particularmente nas notas mais baixas, e uma faixa levemente reduzida (O'KELLY, 1990).

Durante o período Elizabetano (1588-1603) e Jacobino (1603-1625), a flauta doce foi usado para música incidental e no teatro para representar eventos sobrenaturais e cenas pastorais. Os onze anos do período Commonwealth (1649-1660) mostraram o início do declínio na popularidade da flauta doce, embora Charles I incentivasse a prática desse instrumento. Pode-se dizer que o Commonwealth serviu para congelar 
o desenvolvimento do profissionalismo na música e fazer da flauta doce um instrumento mais doméstico (LIRA, 1984).

Durante os últimos anos do século $\mathrm{XVI}$, compositores começaram a designar com alguma consistência que instrumentos eles preferiam. O período de 1680 a 1730 foi o auge para as flautas doces na música inglesa. Livros de exercícios existiam em grande abundância e continham música de alta qualidade. Os livros de instruções destinavam-se a introduzir amadores no universo da flauta doce, mas também é evidente, a partir de um número de composições difíceis disponíveis, que havia alguns músicos virtuosos em outros instrumentos também. As músicas executadas durante este período teve uma grande quantidade de variedade de performances atribuídas às flautas doces. Mesmo versos diferentes em uma mesma peça foram realizados por uma combinação diferente de vozes e flautas doces (BARROS, 2010).

Na segunda metade do século XVII, a flauta doce foi usada na Alemanha em músicas operísticas, geralmente para retratar cenas idílicas, da mesma forma que nos séculos anteriores. Também foi usada em músicas de câmara, o que a fez se tornar cada vez mais popular. Durante o início século XVIII, a flauta doce de agudos era o melhor instrumento da categoria. Sabe-se ainda que elas ainda foram usadas em consortes durante este período a partir de coleções existentes (BENASSI, 2017).

O instrumento entrou em declínio após o século XVIII, sendo usado pela última vez como um som sobrenatural por Gluck em sua ópera Orfeo ed Euridice. Na era romântica, a flauta doce foi quase totalmente substituída pela flauta transversal e pelo clarinete. Uma variante da flauta doce sobreviveu nas salas de concerto do século XIX, em um modelo de flauta doce com chaves conhecido como czakan ou Stockflöte. Esse declínio passou pelo século XIX seguindo a mesma tendência do século anterior (STORI, 2008).

A flauta doce foi revivida por volta da virada do século $X X$ pelos primeiros entusiastas da música, mas usada quase exclusivamente para esse propósito. Foi considerada um instrumento principalmente histórico. Mesmo no início do século 20 , a flauta doce era considerada uma espécie de clarinete. Essa reação não é surpreendente, uma 
vez que o primeiro clarinete foi, em certo sentido, derivado da flauta doce, pelo menos em sua aparência externa (LIRA, 1984).

O eventual sucesso da flauta doce na era moderna é frequentemente atribuída a Arnold Dolmetsch no Reino Unido e a vários estudiosos e artistas alemães. Embora ela fosse responsável por ampliar o interesse para além do primeiro especialista em música do Reino Unido, Dolmetsch estava longe de ser o único responsável pelo renascimento da flauta doce. No continente, os seus esforços foram precedidos pelos dos músicos do Conservatório de Bruxelas, onde Dolmetsch recebeu a sua formação, e pelas atuações da Bogenhausen Artists Band, sediada na Alemanha. Durante o período de 1890-1939, os Bogenhausers tocaram música de todas as idades, incluindo arranjos de música clássica e romântica. Também na Alemanha, os trabalhos de Willibald Gurlitt, Werner Danckerts e Gustav Scheck prosseguiram independentemente dos Dolmetsches. Assim, o avivamento, longe de ser o trabalho de um homem, foi o resultado de várias vertentes vindo e trabalhando juntas (LUFT, 1972).

Carl Dolmetsch, filho de Arnold Dolmetsch, tornou-se um dos primeiros flautistas doces virtuosos da década de 1920. Ele começou a encomendar obras de flautistas doces dos principais compositores de sua época, especialmente para apresentações no festival de Haslemere que seu pai dirigia. Inicialmente, como resultado disso, e mais tarde, como resultado do desenvolvimento de uma escola holandesa de tocadiscos, liderada por Kees Otten, a flauta doce foi apresentada a músicos sérios como um instrumento solo virtuoso tanto na Grã-Bretanha quanto no norte da Europa e, consequentemente, moderno (PAOLIELLO, 2007).

\subsection{OS DOLMETSCH E A FLAUTA DOCE}

\subsubsection{ARNOLD DOLMETSCH}

Arnold Dolmetsch nasceu em 1858 em Le Mans, na província de Sarthe, no oeste da França. Nos dois lados de sua família havia uma tradição de música e construção de instrumentos que remontava ao século XVIII, e desde os primeiros anos Arnold 
recebeu lições de piano e violino e aprendeu a arte de afinar e consertar órgãos com seu avô materno Armand Guillouard. Dos 14 aos 19 anos, trabalhou na oficina da família, Maison Dolmetsch-Guillouard, na Rue de la Préfecture, em Le Mans, e aprendeu a construir e manter instrumentos de cordas e de teclado (O'KELLY, 1990).

Em 1881, após alguns meses de estudo privado com o virtuoso violinista Henri Vieuxtemps, ele ingressou no Conservatório de Bruxelas, onde estudou piano, violino e contraponto. Seus dois anos em Bruxelas tiveram uma profunda influência sobre ele, pois os alunos tinham acesso à coleção de instrumentos antigos do Conservatório e à biblioteca de música antiga. O diretor, François Gevaert, ensinou-Ihe a importância da ornamentação na música antiga e, nos Concertos Históricos realizados para os alunos, Arnold ouviu pela primeira vez performances em violas, viola d'amore, cravos e flautas doces (LIRA, 1984).

Depois de concluir seu curso em Bruxelas, Arnold viajou para Londres e se matriculou no recém-inaugurado Royal College of Music, onde estudou violino com Henry Holmes, composição com Dr. Hubert Parry e harmonia e contraponto com o Dr. Frederick Bridge, organista e mestre de coro da Abadia de Westminster. O diretor, Sir George Grove, incentivou seu crescente interesse pela música antiga e Arnold explorou a excelente biblioteca de manuscritos e livros impressos do Colégio dos séculos XVI a XVIII (STORI, 2008).

Ao deixar o Royal College of Music, Arnold garantiu um posto de professor como professor de violino em part-time no Dulwich College, no sudeste de Londres. Durante esse período, ele começou a assistir a leilões e a navegar em livrarias de antiquários e a montar sua própria biblioteca de primeiros tratados de música e música. Ele ensinou seus alunos a tocar violino usando métodos do século XVII e copiou músicas de Purcell, Corelli e Handel para eles se apresentarem nos shows anuais dos alunos (BENASSI, 2017).

Em 1889 Arnold adquiriu uma viola d'amore feita por Testore em 1736 e depois de consultar um tratado de sua biblioteca, restaurou-a para tocar. Enquanto procurava as bibliotecas do Museu Britânico e do Royal College of Music para tocar música 
autêntica, ele encontrou um tesouro de música inglesa dos séculos XVI e XVII para o consorte de violas. Esta descoberta provou ser um ponto de viragem e depois disso ele resolveu dedicar a sua vida à restauração da música antiga e dos instrumentos para os quais foi escrita (BARROS, 2010).

Em 1891, Arnold havia restaurado uma viola d'amore, um alaúde do século XVI, uma consorte de violas, uma espingarda do século XVII, um clavicórdio do século XVIII e um duplo cravo manual e treinou sua família e alguns alunos cuidadosamente escolhidos para tocá-los. Em 27 de abril de 1891, ele apresentou seu primeiro concerto independente de música antiga no Princes Hall, Piccadilly. Foi um sucesso esgotado e triunfante - o Early Music Renaissance havia chegado (O'KELLY, 1990).

Ao longo da década de 1890, Arnold fez sua série pioneira de recitais de conferências. De especial significado foram os apresentados no "The Fitzroy Settlement", Bloomsbury; Barnard's Inn, Holborn e em "Dowland", sua casa em West Dulwich. Entre o público estavam os artistas, escritores, poetas, estudiosos e artesãos do Movimento de Artes e Ofícios liderado por William Morris e Edward Burne-Jones. Durante esse período, Arnold também começou a projetar e construir seus primeiros instrumentos, baseados nos modelos antigos que ele havia restaurado. Estes incluíam vários clavicórdio, um dos quais foi comprado por Edward Burne-Jones, que o decorou para sua filha Margaret Mackail; e três pianos "Beethoven", o segundo dos quais encomendado por Cecil Rhodes para sua casa Groote Schuur na Cidade do Cabo, na África do Sul. Foi por sugestão de William Morris que Arnold construiu o primeiro grande cravo dos tempos modernos para a Mostra da Sociedade de Artesanato e Exibição na New Gallery em Regent Street, em 1896. Foi um verdadeiro instrumento de Artes e Ofícios com decorações de Herbert Horne, Selwyn Image e Helen Coombe. Em 1899, Arnold foi eleito membro do Art Workers Guild, o primeiro fabricante de instrumentos musicais a ser admitido (PAOLIELLO, 2007).

De 1905 a 1910, Arnold trabalhou para os famosos fabricantes de pianos Chickering and Sons of Boston. Um departamento de instrumentos foi criado para ele, com a ajuda de artesãos experientes e acesso aos melhores materiais. Cravos, incluindo um instrumento para Busoni, virginals, clavichords, alaúdes e violas foram construídos, e 
muitos de seus melhores instrumentos datam deste período. Em 1910, uma recessão comercial forçou a Chickering a fechar seu antigo departamento de instrumentos, e Arnold e sua família voltaram para a Europa, onde ele trabalhou para a fábrica de pianos Gaveau, perto de Paris, de 1911 a 1914. Em fevereiro de 1914, com a guerra iminente no horizonte, a família Dolmetsch deixou a França para Londres e se estabeleceu em Hampstead (LUFT, 1972).

Os últimos 23 anos de Arnold em Haslemere foram repletos de conquistas. Em 1919, após a perda de sua antiga flauta doce de agudos por Bressan em uma plataforma na estação de Waterloo, ele produziu com sucesso a primeira flauta doce dos tempos modernos, após quatro meses de experimentos. Isto foi seguido pela recriação de flautas doces de soprano, tenor e baixo, e o consorte completo de flautas doces fez sua estreia no Haslemere Festival de 1926, tocando música elisabetana em cinco partes (PAOLIELLO, 2007).

O Festival Haslemere surgiu pela primeira vez no verão de 1925. Tendo retornado de uma exaustiva excursão no outono anterior, Arnold um dia comentou que estava cansado de fazer turnês e que, a partir de então, as pessoas teriam que vir até ele, em vez de irem para eles. Com base neste acaso, surgiu o Festival de Haslemere da música antiga, de 1925 a 2001, um inesquecível retorno de 77 anos. Com fundos generosamente doados por Marco Pallis, um amigo e aluno, um ateliê foi construído ao lado de Jesses em 1921. Instrumentos fluíram deste espaço criativo durante os anos 20; flautas doces e outros instrumentos eram produzidos para um número cada vez maior de clientes entre os quais George Bernard Shaw, Lorde Berners, Robert Bridges, Violet Gordon Woodhouse, Sir Henry Wood, Ezra Pound, Roger Fry e Dorothy Swainson (BENASSI, 2017).

Arnold celebrou seu $80^{\circ}$ aniversário em 24 de fevereiro de 1938 no salão do Art Workers Guild, onde foi presenteado com a cruz do Chevalier de la Legion d'Honneur, em reconhecimento aos seus serviços à música e à arte francesa em particular. Além do grande número de instrumentos finos que são apreciados em museus e coleções particulares em todo o mundo, Arnold é lembrado por seu trabalho acadêmico inovador (STORI, 2008). 


\subsubsection{CARL DOLMETSCH}

Carl Dolmetsch nasceu em 1911 em Fontenay-sous-Bois, na França e era o mais novo dos quatro filhos de Arnold e Mabel. De 1917 até seu casamento em 1937, Jesses foi sua casa, e após a morte de sua mãe em 1963, ele retornou para a casa da família, permanecendo lá até sua morte em 1997 (PAOLIELLO, 2007).

Carl participou da música da família a partir dos 4 anos, tocando violão e depois violino, e passou a estudar com Carl Flesch e Antonio Brosa. Ele fez sua estreia no gravador durante o segundo Haslemere Festival em 1926, quando participou de uma apresentação do Concerto de Brandemburgo de Bach $n^{\circ} 4$, tocando ao lado de seu irmão Rudolph (flauta doce) e seu pai Arnold (violino solo). Ele teve que aprender a técnica da flauta doce e a dominar em apenas cinco semanas, desde que ele estava substituindo a curto prazo, Miles Tomalin, que foi incapaz de cumprir o compromisso. Não muito depois deste evento emocionante, Arnold entregou toda a responsabilidade pelo projeto e produção da flauta doce para Carl, embora ele tivesse apenas quinze anos na época (LUFT, 1972).

A partir deste momento, Carl dedicou a sua vida à flauta doce e, através da sua habilidade como designer, artesão e intérprete virtuoso, elevou o status do instrumento, de modo que foi mais uma vez encarado com seriedade pelo mundo musical, como anteriormente no século XVIII. Entre 1939 e 1989, Carl participou de quarenta e cinco concertos em Wigmore Hall, Londres, com destaque para os trabalhos especialmente encomendados para falutas doces pelos principais compositores do século 20, entre os quais Lennox Berkeley, Edmund Rubbra, Bowen, Arnold Cooke, William Matthias, Gordon Jacob, Hans Gál e Jean Françaix. Este repertório moderno, com novos desafios técnicos, tonais e expressivos, garantiu um futuro brilhante para a flauta doce (STORI, 2008).

Por mais de 60 anos, Carl teve uma parceria musical com o cravista e pianista Joseph Saxby. A dupla Dolmetsch-Saxby fez turnê mundial, visitando a Europa, Austrália, Nova Zelândia, Japão, América do Sul, Canadá e EUA, onde realizaram pelo menos 20 tours de costa a costa ao longo dos anos. Após a morte de seu pai em 1940, Carl 
tornou-se diretor do Festival Haslemere, um papel que ele cumpriu com imaginação e talento até 1996. Ele ampliou o escopo do festival, apresentando concertos para escolas, que entretinham e educavam muitas gerações de crianças (BARROS, 2010).

Uma das contribuições mais importantes de Carl para o mundo musical foi o design e a introdução da flauta doce de plástico. Durante a Segunda Guerra Mundial, a oficina de Dolmetsch cessou a produção de instrumentos musicais e passou a fabricar peças para armas de aeronaves. Mais de 2,5 milhões de componentes foram produzidos a partir de fibra de vulcanite e materiais plásticos com um alto grau de precisão. Carl percebeu que a mesma tecnologia poderia ser usada para a produção de gravadores e, em 1945, fez os desenhos para as primeiras flautas doces de plástico Dolmetsch, que partiram da linha de produção em 1946. Eles compartilhavam as mesmas dimensões dos instrumentos de madeira, e a entonação e qualidade do som eram de alto padrão. Devido à sua acessibilidade, essas flautas doces de plástico foram logo introduzidas nas escolas, onde revolucionaram a educação musical para gerações de crianças. Nos anos 50 e 60, a flauta doce se tornara uma palavra doméstica dentro das escolas musicais (LIRA, 1984).

Em 1954 Carl foi nomeado CBE por seu trabalho em educação musical e em 1960 o grau de honorário D. Litt. foi conferido pela Universidade de Exeter. Como seu pai antes dele, Carl era um membro da Art Workers Guild e em 1989 foi eleito mestre da guilda. O funeral de Carl ocorreu na quinta-feira, 17 de julho de 1997, na Igreja de São Bartolomeu, Haslemere, coincidentemente e apropriadamente no dia do primeiro concerto do $73^{\circ}$ Festival de Haslemere (PAOLIELLO, 2007).

\subsection{A FLAUTA DOCE NOS DIAS ATUAIS}

\subsubsection{TIPOS DE FLAUTAS DOCES}

As flautas doces são nomeados de acordo com o tamanho do instrumento. Existem dois esquemas de nomeação, um ligado ao uso histórico do instrumento, o outro à voz humana que mais se assemelha. Segundo Frank (1980), os tipos de flautas doces existentes são: 
- Soprano: este é o instrumento mais comum hoje e possui afinação em C, o que significa que a nota mais baixa possível é um C. Por ser um pouco estridente, em reprodução avançada é frequentemente restrito a uma linha descendente ou acima da melodia principal. Embora realmente soe uma oitava mais alta por causa do timbre, parece que ela é lançada similarmente a um soprano humano. O espaçamento relativamente curto entre os furos e o baixo preço do instrumento o tornaram o primeiro instrumento ideal nas escolas.

- Alto: é o principal instrumento de melodia em trabalhos avançados, assim como os agudos estão na música coral da igreja, onde o mesmo soa o mais próximo de uma voz humana alta. $\mathrm{O}$ instrumento possui afinação em $\mathrm{F}$. $\mathrm{O}$ alcance nas de agudos nessas flautas doces é maior do que o descendente e isso, junto com o preço mais alto, o torna um instrumento para aqueles que estão começando a progredir.

- Tenor: possui o dobro do tamanho do soprano e, portanto, limitando sua utilização por crianças ou adolescentes. O furo mais baixo é controlado por uma ou duas chaves devido ao alongamento. Ela também possui afinação em $\mathrm{C}$, mas em uma oitava abaixo do instrumento soprano.

- Baixo: é a maior flauta doce comumente encontrada. É um instrumento que possui afinação em $\mathrm{F}$, possui cerca de três vezes o comprimento da flauta doce soprano. Nela, o buraco mais baixo é controlado por chaves.

- Outros tamanhos: os músicos especialistas também podem utilizar flautas doces menores, onde as mesmas são chamadas de sopranino e greatbass. Flautas doces intermediárias em D, B-bemol, G e E-bemol existem, mas não serão encontradas na música elementar. 
Figura 1 - Tipos de flautas doces existentes

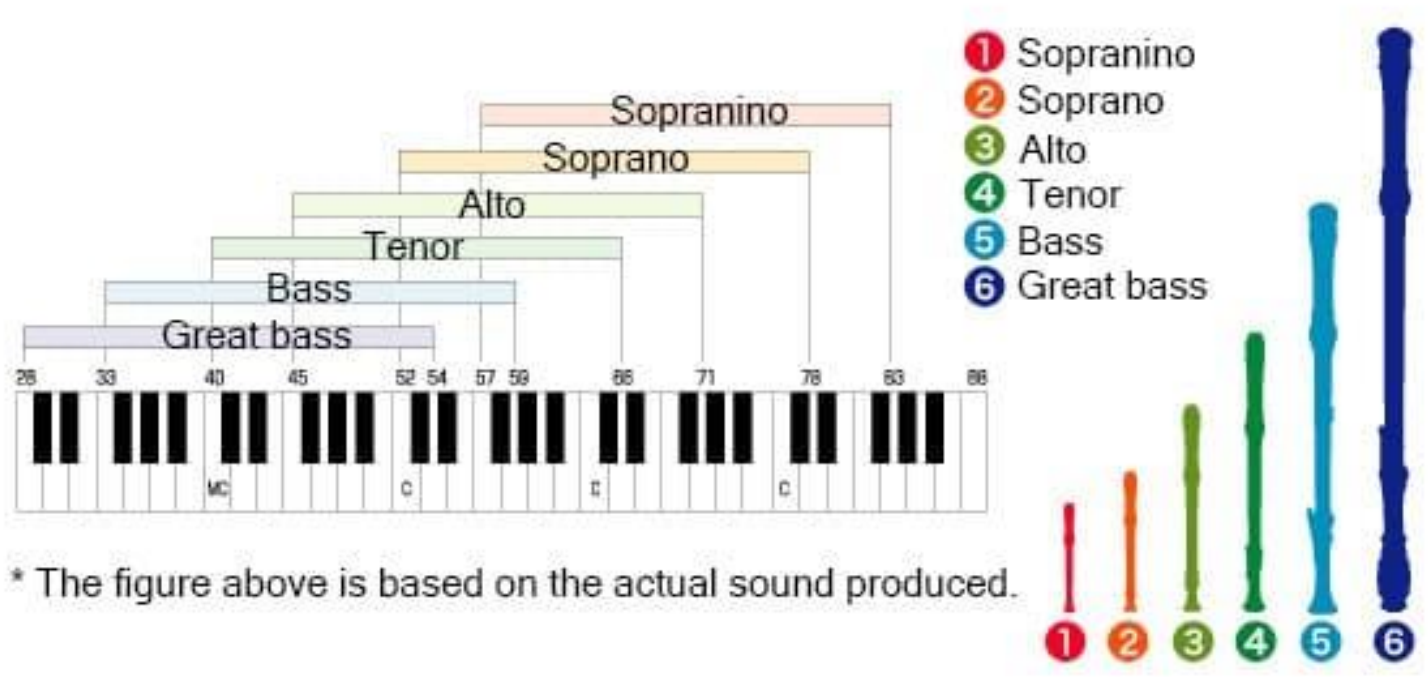

Fonte: Yamaha (2019)

\subsubsection{CONSTRUÇÃO E OPERAÇÃO DAS FLAUTAS DOCES}

As flautas doces de alta qualidade são feitas de uma variedade de madeiras nobres; já as flautas doces de plástico são produzidas em grandes quantidades. Isso porque os plásticos são mais baratos e exigem menos manutenção, e as flautas doces de plástico com qualidade podem ser tão boas quanto as flautas doces de madeira de baixo custo. As flautas doces de plástico podem ser esterilizadas por imersão em um desinfetante suave, o que pode ser desejável se forem compartilhadas entre os músicos. As flautas doces para iniciantes, o tipo geralmente encontrado em conjuntos de crianças, são de plástico e com preços mais acessíveis no mercado (ROSA, 1999).

A flauta doce é utilizada longitudinalmente à boca do músico, e não para o lado como a flauta transversal. A respiração do músico é comprimida em uma corrente de ar linear por um canal cortado no bocal do instrumento, de modo a percorrer todo esse duto. Saindo desse campo, o ar é direcionado contra uma aresta dura, chamada de "labium", que faz com que a coluna de ar dentro do tubo ressonador oscile com ondas estacionárias. Ao contrário de assobios simples, onde os buracos são progressivamente desimpedidos, a flauta doce usa um meio com orifícios e 
bifurcações para modificar a posição dos nós. As figuras a seguir ilustram o funcionamento da flauta doce durante a sua execução (CUERVO, 2004a).

Figura 2 - Passagem de ar no bocal da flauta doce

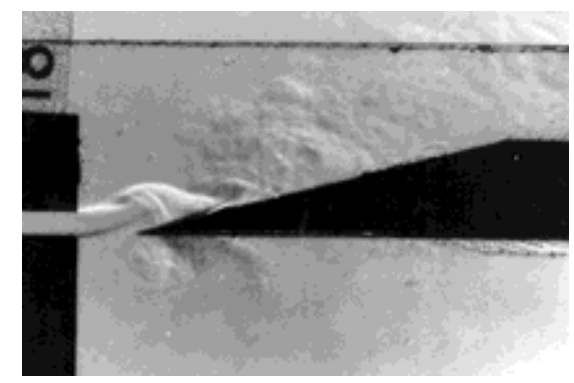

Fonte: Quinta Essentia (2019)

Figura 3 - Partes de uma flauta doce

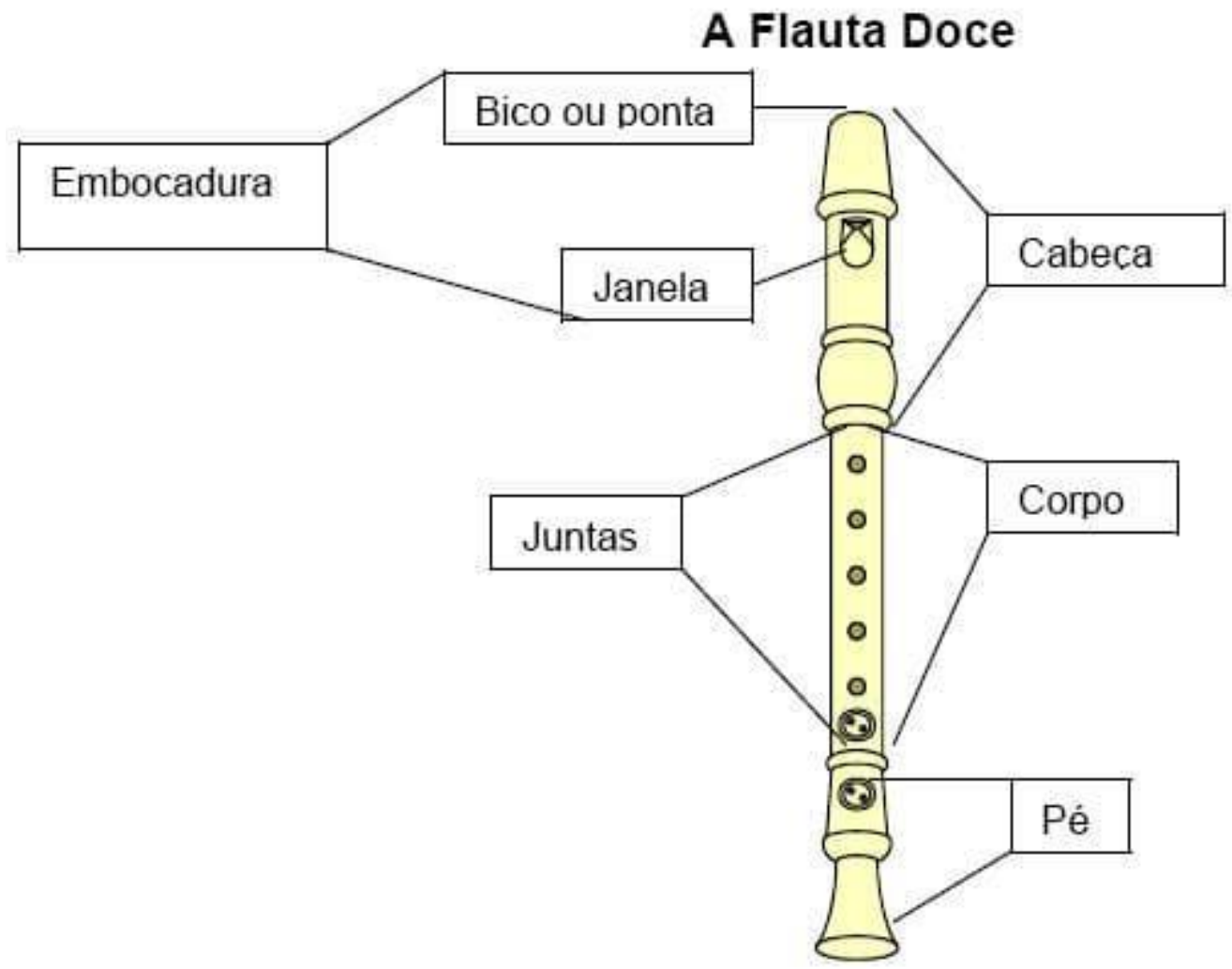

Fonte: Só Flauta Doce Web (2011) 


\subsubsection{NOTAÇÃO E PITCH}

As flautas doces utilizadas nas escolas são utilizadas no campo de concertos. A família de flautas doces não é transponível, o que significa que a partitura para uma flauta doce é quase sempre gravada na tecla em que é tocada. Um C escrito na partitura realmente soa como C. Registradores são chamados de "dedos C" ou "dedos F", dependendo da nota mais baixa. Isso implica que o músico deve aprender dois conjuntos diferentes de dedilhados semelhantes, um para as flautas doces em $\mathrm{C} \mathrm{e}$ outro para as flautas doces em F. Um músico pode facilmente passar de um flauta doce com dedos em $\mathrm{C}$ para outro, e de uma com dedos em $\mathrm{F}$ para outro, mas alternar entre os dois requer conhecimento acerca dos dois conjuntos de dedilhados ou uma capacidade de transpor a música durante a execução (WEILAND; VALENTE, 2006).

As flautas doces soprano transpõem a oitava, assim como a baixo. Em partituras modernas, as transposições de oitava podem ser indicadas pela adição de uma pequena figura "8" acima da clave de sol ou grave nas partes soprano ou baixo, mas no passado e ainda comumente hoje, as transposições não são indicadas e são assumidas no contexto. Os instrumentos de baixo usam a clave de fá, mas podem ocasionalmente usar a clave de sol e transpor uma oitava. Os outros três instrumentos comuns usam a clave de sol (CUERVO, 2007).

Para facilitar a transição para a reprodução de uma flauta doce de agudos/alto, algumas músicas educacionais são escritas com os dedos em $\mathrm{C}$ e, nesse caso, o instrumento transpõe um quarto. Como regra geral, as flautas doces soam uma oitava acima da voz humana após a qual são nomeados, ou seja: uma flauta doce soprano é uma oitava acima da voz soprano, a alto uma oitava acima da voz de alto, e assim por diante. $\mathrm{O}$ tom moderado e os harmônicos limitados da flauta doce permitem um som mais profundo (WEILAND; SASSE; WEICHSENBAUM, 2008).

\subsubsection{DEDILHADO}

O alcance de uma flauta doce moderna costuma ser de duas oitavas, exceto em peças virtuosas. Notas acima desta faixa são mais difíceis de tocar, e os dedilhados exatos 
variam de instrumento para instrumento. Portanto, sua execução varia de acordo com a técnica utilizada pelo músico para atingir tal nota (CUERVO, 2004b).

Os graus mais baixos da escala cromática, sendo um semitom e um terço menor acima da nota mais baixa, são tocados cobrindo apenas uma parte de um buraco, uma técnica conhecida como "half-holing". A maioria dos instrumentos modernos são construídos com furos duplos ou chaves para facilitar a execução dessas notas; esses buracos duplos são ocasionalmente encontrados em instrumentos barrocos, onde até o buraco do terceiro dedo da mão esquerda pode ser dobrado. Outros graus de escala cromática são tocados pelos chamados dedilhados de "garfo", descobrindo um buraco e cobrindo um ou mais dos que estão abaixo dele. Os dedilhados em garfo têm um caráter tonal diferente das notas diatônicas, dando à falta doce um som um pouco irregular. As flautas doces do tipo baixo podem ter uma única tecla para $\mathrm{C} / \mathrm{F}$ baixo, mas não baixo $\mathrm{C} \#$ / $\mathrm{F} \#$, tornando esta nota praticamente impossível de ser reproduzida. Teclas baixas duplas, permitindo tanto $\mathrm{C} / \mathrm{F}$ quanto $\mathrm{C \#}$ / $\mathrm{F} \#$, são mais ou menos comuns hoje em dia (WEILAND; VALENTE, 2006).

A maioria das notas na segunda oitava e acima é produzida pela abertura parcial do thumbhole na parte de trás da flauta doce, uma técnica conhecida como "pinching". Existem dois métodos básicos para isso: afastar o polegar do buraco ou dobrar o polegar. O primeiro método usa apenas a pele do polegar para definir a abertura, enquanto o segundo método também usa a borda da unha. A última técnica permite uma melhor sensação e, portanto, o controle do tamanho da abertura. A colocação do polegar é crucial para o tom, entonação e estabilidade dessas notas e varia à medida que as notas aumentam o tom, inviabilizando a perfuração de um buraco duplo para o polegar. Para tocar as notas no segundo registro e acima, o músico geralmente deve soprar mais ar no instrumento ou utilizar a língua para aumentar a vazão de ar, para assim atingir os harmônicos superiores do instrumento (WEILAND; SASSE; WEICHSENBAUM, 2008). 
Figura 4 - Estrutura do dedilhado em uma flauta doce

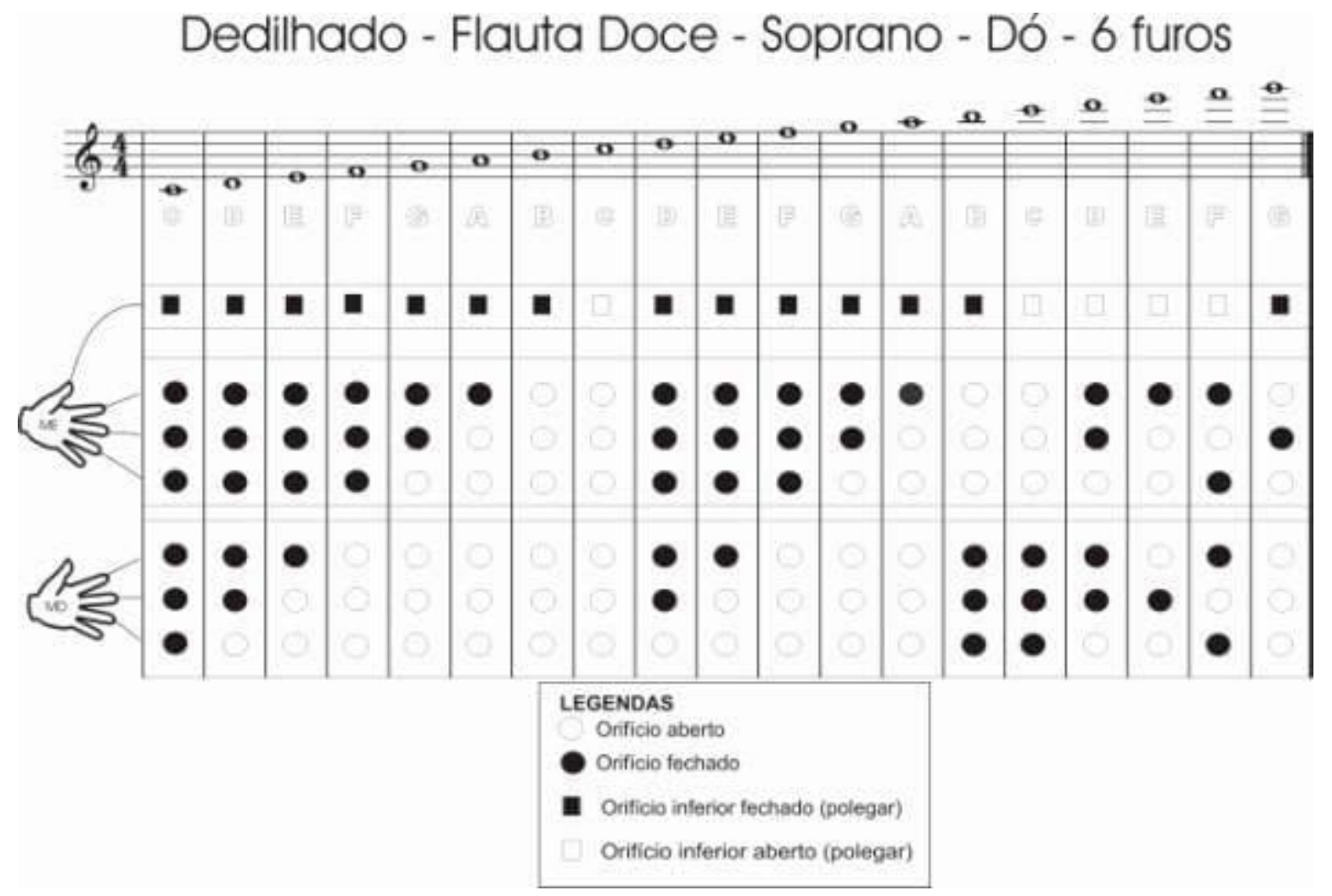

Fonte: Ivan Meyer (2019)

Mudanças na dinâmica na flauta doce não são fáceis de alcançar se o músico estiver acostumado a outros instrumentos de sopro. A crença geral é que se o músico sopra mais forte para tocar mais alto, ou mais suavemente para tocar mais suave, o tom muda e a nota sai de sintonia, e ao contrário da flauta transversal, o músico não pode mudar a posição da boca em relação ao lábio para compensar e, portanto, o músico não é capaz de mudanças dinâmicas. Mudanças sutis na pressão do vento são possíveis se o músico tiver um bom ouvido para sintonizar e souber o quão difícil o instrumento pode ser pressionado antes que as alterações de tom se tornem perceptíveis. Na flauta doce, é melhor pensar no tom de controle da respiração e nos dedos controlando a dinâmica. Por exemplo, descansando os dedos levemente nos furos, a respiração vaza ao redor deles, levantando o tom; e a resultante mudança instintiva na pressão da respiração para trazer o tom de volta também diminui o volume. A flauta doce é notável por sua sensibilidade à articulação (CUERVO, 2007). 


\subsubsection{USO DA FLAUTA DOCE NA EDUCAÇÃO MUSICAL}

O atual nível de aceitação da flauta doce a torna, provavelmente, um dos instrumentos mais tocado de todos, porém um dos menos praticado. Sendo assim, é de responsabilidade do educador se utilizar da flauta doce em suas aulas de música para elevar este padrão de aceitação. Uma das principais tarefas da flauta doce reside principalmente no campo da educação. Isso se deve ao fato de que grande parte das crianças brincam com flauta doce em suas rotinas. Devido á essa popularidade, sua utilização como instrumento em escolas de música contribui de forma considerável no engajamento dos músicos aspirantes (ROSA, 1999).

Sendo assim, a flauta doce vem sendo aceita, a cada dia que passa, como um instrumento extremamente adequado para lecionar música nas escolas. Isso se deve ao fato de que a flauta doce é barata, é um instrumento musical sério com o seu próprio repertório e combina bem com vozes e outros instrumentos musicais; é bastante fácil os músicos tocarem suas músicas em conjunto, sem muitas dificuldades de simultaneidade (CUERVO, 2004b).

Mas a relativa facilidade com que os passos iniciais são dados pelos aspirantes na música não reflete totalmente num aprendizado mais rápido. Isso se deve ao fato de que demanda treinamento por parte do aspirante para produzir um som no instrumento ou para aprender os dedilhados básicos. No entanto, quando se trata de dominar as notas agudas, entonação e produção de som vibrato, um estudo mais aprofundado mostra-se necessário. É por isso que existe um contraste no desempenho entre o aspirante e um músico mais experiente na execução da flauta doce, como com qualquer outro instrumento (FRANK, 1980).

Nas escolas de música, a flauta doce pode oferecer bons resultados se usada corretamente. Os problemas ocorrem quando os professores, com pouca ou nenhuma experiência, tentam ensinar grandes turmas. Para se tirar o máximo proveito da flauta doce, a mesma deve ser ensinada por professores que já tenham alguma ideia sobre o instrumento e com aulas ministradas para turmas pequenas (CUERVO, 2004a). 
Existe uma vantagem em se agrupar os alunos que irão aprender flauta doce quando se trata de entonação, pois uma turma grande tende a produzir resultados mais expressivos. Isso porque haverá a possibilidade de se comparar as entonações empregadas por cada aluno, a fim de que se possa normalizar todos a uma entonação ideal para a execução musical. Por outro lado, um problema que se pode ter é o de encontrar instrumentos adequados, onde as flautas doces de plástico apresentam resultados melhores do que aqueles obtidos com as flautas doces de madeira (WEILAND; VALENTE, 2006).

As flautas doces são introduzidas nas escolas de música como um instrumento para iniciação musical. A razão para esse seu uso específico é selecionar quais crianças têm aptidão musical para continuar com um instrumento musical mais elaborado ou complexo. A este respeito, a flauta doce é mal utilizada, pois todo o seu potencial como instrumento musical tende a não ser percebido por ser descartado cedo demais e, como resultado, muitas experiências boas e gratificantes são perdidas (FRANK, 1980).

Em meados do século $\mathrm{XX}$, o compositor e educador musical alemão Carl Orff popularizou a flauta doce para uso em escolas como parte dos programas da OrffSchulwerk nas escolas alemãs. A obra musical de cinco volumes de Orff Music for Children contém muitas peças para flautas doces, com a presença de outros instrumentos também. Elas também são relativamente fáceis de se tocar em um nível básico, porque a produção de som precisa apenas de respiração, e o pitch é basicamente determinado pelo dedilhado. Assim, a flauta doce exige que os estudos a ela direcionados funcionem bem e em sintonia, com um estudo significativo a ser realizado em nível avançado ou profissional (ROSA, 1999).

\section{CONCLUSÃO}

Muitos conhecem a flauta doce como um tubo de plástico que é vendido em lojas ou distribuído nas aulas de música ou como um brinquedo ou como um introdutor a instrumentos mais aperfeiçoados. Devido à sua aparência simples e sua execução fácil, ele não tem a reputação de ser um instrumento atrativo. Mas isso não significa 
que ele não tenha uma relevância significativa dentro do universo musical, onde grandes músicos buscaram a inspiração da música na flauta doce.

Séculos antes do clarinete, da gaita e da tuba serem inventadas, os primeiros músicos tocavam flautas doce. $\mathrm{O}$ exemplo sobrevivente mais antigo do instrumento remonta à Europa do século XIV. O rei Henrique VIII é mais conhecido por seus notórios casamentos do que por seus talentos musicais. Mas ele também foi um compositor realizado, publicando várias músicas e obras instrumentais durante sua vida. Seu passatempo musical levou a uma ambiciosa coleção de instrumentos: antes de morrer em 1547, Henrique VIII havia adquirido 76 gravadores.

A flauta doce foi um membro importante da família dos instrumentos de sopro durante o período barroco, sendo incorporada em várias composições da época. Na ópera, o som claro e doce do gravador era usado para evocar temas eróticos e imagens pastorais. A flauta doce era tão popular durante o século XVI que era usada para ilustrar obras literárias populares na época.

Uma razão pela qual as flautas doces são uma escolha popular para as aulas de música é sua praticidade e importância na execução musical. Mas a forma simples do instrumento se presta a vários formatos e tamanhos, possibilitando assim opções para aqueles que enxergam na flauta doce um potencial instrumento musical.

Enquanto a flauta doce é tecnicamente um tipo de flauta, é a flauta transversal que se associa ao termo "flauta" nos dias de hoje. A flauta doce, com sua falta de alcance e volume, não teve chance contra o som da flauta transversal, que alcançava alturas consideráveis nas obras musicais. No decorrer do século XIX, a flauta doce foi eliminada da orquestra moderna.

O status da flauta doce como uma relíquia de uma época passada é o que ajudou a torná-la atrativa novamente. Na virada do século 20 , museus exibiam instrumentos históricos e o interesse pela música pré-clássica começou a aumentar. Isso ajudou a preparar o caminho para que a flauta doce retornasse como um instrumento revitalizado. Logo, começou a aparecer nos arranjos da música antiga. Por volta de 
meados do século 20, a flauta doce sofreu sua transformação estrutural, onde o plástico passou a ser utilizado para sua fabricação. Esse material produzia um instrumento que era mais resistente do que sua antecessora de madeira e muito mais barata. Não só isso, mas a qualidade do som não sofreu com essa mudança.

Os professores de música podem ter mais facilidade em divulgar a flauta doce como um instrumento de moda se eles desenvolverem sua conexão com música moderna. Embora muitos músicos usem o instrumento em seus trabalhos musicais, nem todos a utilizam como instrumento principal.

O compositor alemão Carl Orff é mais conhecido por revolucionar a educação musical infantil. Um dos princípios centrais de seu estilo de ensino ensinava que, se as crianças pudessem cantar as notas que estavam tocando, teriam mais facilidade para aprender a música. O gravador de soprano, semelhante ao alcance da voz de uma criança, era um ajuste natural. Suas ideias estavam se tornando populares na mesma época em que as flautas doces mudavam para o plástico, o que significava que mais escolas poderiam comprá-las em grandes quantidades.

Assim, esse presente estudo, além de mostrar a história e as características da flauta doce, mostrou também que a flauta doce se mostra como uma alternativa eficiente para se otimizar o aprendizado da música, mais especificamente para crianças. Através de uma divulgação e uso de técnicas de ensino voltadas para o ensino da música para a flauta doce, os músicos tendem a considerá-la não como um instrumento da moda ou de brinquedo, mas como um instrumento rela e de grande valor musical.

\section{REFERÊNCIAS}

BARROS, Daniele Cruz. A flauta doce no século XX: o exemplo do Brasil. Recife: Ed. Univ. UFPE, 2010. 
BENASSI, Claudio Alves. A flauta doce hoje: O instrumento e suas técnicas expandidas no repertório de música contemporânea. Saarbrücken: Novas Edições Acadêmicas, 2017.

CUERVO, Luciane. A construção do repertório para flauta doce em um projeto de inclusão social. In: SEMINÁRIO NACIONAL DE ARTE E EDUCAÇÃO, 18ㅜ, 2004a, Montenegro. Anais. Montenegro: FUNDARTE, 2004a, p.199.

CUERVO, Luciane. A Música Brasileira para Flauta Doce: uma proposta de democratização do acesso ao repertório. In: ENCONTRO NACIONAL DA ASSOCIAÇÃO BRASILEIRA DE EDUCAÇÃO MUSICAL, 13ㅜ, 2004b, Rio de Janeiro. Anais. Rio de Janeiro: ABEM, 2004b, p.635-641.

CUERVO, Luciane. A Expressão da Musicalidade com a Flauta Doce: Reflexões e Estratégias. In: ENCONTRO NACIONAL DA ASSOCIAÇÃO BRASILEIRA DE EDUCAÇÃO MUSICAL e CONGRESSO REGIONAL DA ISME NA AMÉRICA LATINA, XVI, 2007, Mato Grosso do Sul. Anais. Mato Grosso do Sul: ABEM, 2007.

FRANK, Isolde Mohr. Pedrinho toca flauta: uma iniciação musical através da flauta doce para crianças. São Leopoldo: Sinodal, 1980.

IVAN MEYER. Digitação - Flauta doce - seis orifícios? Disponível em: <http://www2.ivanmeyer.com.br/forum/index.php?showtopic=17271>. Acesso em: 13 fev. 2019.

LIRA, Ilma. Rumo a um novo papel da flauta doce na educação musical brasileira. 1984. 106 f. Dissertação (Mestrado em Artes), Departamento de Música, Universidade de York, Inglaterra, 1984.

LUFT, Lya Fett. Flauta doce: tema e variações. Porto Alegre: Sulina, 1972.

O’KELLY, Eve. The Recorder Today. Cambridge: Cambridge University Press, 1990.

PAOLIELLO, Noara. A flauta doce e sua dupla função como instrumento artístico e de iniciação musical. 2007. 48 f. Monografia (Licenciatura Plena em Educação Artística - 
Habilitação em Música), Centro de Letras e Artes, Universidade Federal do Estado do Rio de Janeiro, Rio de Janeiro, 2007.

QUINTA ESSENTIA. Como a flauta funciona. Disponível em: <http://quintaessentia.com.br/en/artigo/flauta-funciona/>. Acesso em: 13 fev. 2019.

ROSA, Nereide Schilaro Santa. Flauta doce: método de ensino para crianças. São Paulo: Editora Scipione, 1999.

SO FLAUTA DOCE WEB. Partes da flauta doce. Disponível em: <http://soflautadoceweb.blogspot.com/2011/12/partes-da-flauta-doce.html>. Acesso em: 113 fev. 2019.

STORI, Regina. A Flauta Doce no Ensino Superior: Um Relato de Experiência. In: Simpósio Acadêmico de Flauta Doce, I, 2008, Curitiba. Relato de Experiência, Anais. Curitiba: Escola de Belas Artes do Paraná, 2008.

WEILAND, Renate Lizana; SASSE, Ângela; WEICHSENBAUM, Anete. Sonoridades Brasileiras: método para flauta doce soprano. Curitiba: DeArtes, UFPR, 2008.

WEILAND, Renate Lizana; VALENTE, Tamara da Silveira. Aspectos Figurativos e operativos da aprendizagem musical de crianças e pré-adolescentes, por meio do ensino de flauta doce. Dissertação (Mestrado). Universidade Federal do Paraná, PPGEDU. Curitiba: UFPR, 2006.

YAMAHA. The origins of the Recorder: Varieties of recorder. Disponível em: $<$ https://www.yamaha.com/en/musical_instrument_guide/recorder/structure/structure 004.html>. Acesso em: 13 fev. 2019.

Enviado: Abril, 2020.

Aprovado: Maio, 2020. 